\title{
OS CRIMES E A LOUCURA DOS A.LLEMÃES
}

\section{Conferencia pronunciada em Sertãozinho}

Para estudo dos crimes dos allemães na actual tormenta que se desencadeou sobre a Europa, cumpre-me, antes de tudo o mais, apresentar minhas idéas sobre o Direito Internacional. 'Sou, neste assumpto, o que se denomina modernamente um simplicista. Minhas opiniões sobre a materia são as de um catholico que applica ás nações a regra de Christo: "Amai-vos uns aos outros". Todos queremos viver, todos queremos melhorar nossas condições de existencia, todos somos dotados de sociabilidade, todos temos a tendencia a aperfeiçoar-nos. Para isto foram organizados os Estados, para isto formou-se a sociedade civil, e, para realização completa deste nosso desejo, deveremos procurar manter, entre os povos, a mesma união que ha entre os homens nos Estados adiantados, civilizados. Entretanto a guerra se torna necessaria, já nos casos de affronta ao brio nacional, pois, de facto, se tracta então da defesa da honra, já nos demais casos de ataque directo, em que mais claro ainda se torna o direito de legitima defesa.

Não comprehendo, e é repellida pela consciencia humana, a guerra de conquista, o ataque para opprimir os fracos. O que acabo de dizer, parece acceito pacificamente no Direito das Gentes, ao estabelecerem os mestres as regras que devem ser seguidas na guerra. Não ha uma moral para o individuo differente da que rege as relações entre os povos, proclamou em paginas de monumento mais perenne do que o bronze, em Buenos Aires, a Aguia de Haya; e as cautelas que o exercicio do direito de defesa 
deve ter nas relações individuaes, são as mesmas que se tornam indispensaveis nas internacionaes, na guerra. A declaração de Petrogrado de 11 de Dezembro de 1868, adoptada por todos os Estados da Europa, estabeleceu "que os progressos da civilização devem ter como consequencia attenuar, quanto possivel, as calamidades da guerra; que o unico fim legitimo que os Estados devem se propor, durante a guerra é o enfraquecimento das forças militares do inimigo; que este fim seria ultrapassado pelo emprego de armas que aggravassem inutilmente os soffrimentos de homens postos fóra de combate, ou tornassem sua morte inevitavel; que o emprego de taes armas seria, deśde então, contrario ás leis da humanidade..." Os delegados dos Estados europeus, reunidos em Bruxellas em Julho e Agosto de 1874, firmaram, no art. 12 de seu projecto, que "as leis da guerra não reconhecem aos belligerantes um poder illimitado quanto aos meios de damnificar o inimigo." No mesmo sentido, a tão nossa conhecida conferencia de Haya. A nação nossa amiga, a America do Norte, declarou, nas Instrucções de 1863, que "as necessidades militares não ąutorizam a practicar actos crueis", e accrescentou que "a guerra não tolera nenhum acto de hostilidade de natureza a torhar, sem necessidade, difficil a volta á paz". Foi por isto que o Direito das Gentes moderno condemnou todos os processos barbaros, e entre elles mencionam essas mesmas instrucções ferir ou maltratar o inimigo que se rende (hostes dum vulnerati, fratres); matar os feridos, proclamar, para intimidar (notae bem) que não será dado quartel ao inimigo; practicar actos de crueldade pelo prazer da vingança..."

Do mesmo modo se manifestou, inutil é dizel-o, a conferencia de Haya. Foram condemnados os projecteis explosivos, os gazes asphixiantes (que muitos julgam invenção dos allemães durante a ultima guerra, e de que 
são apenas cultores), o veneno, e firmou-se que a guerra deve tractar de pôr o adversario fóra de combate, e náo de o matar, ou de o maltratar. Foi estabelecido que nenhum ataque deve ser feito ás pessoas que não se podem defender, crianças, velhos e mulheres, nem ás cidades abertas, ou que não oppõem uma séria resistencia. A perfidia, sob qualquer fórma, foi julgada condemnavel. Ora, claro é que as leis da guerra são as mesmas que regem a defesa nas relaçõs individuaes, na qual deve ser guardada a moderação que sempre foi recommendada pelos moralistas, e que é prescripta pelas leis dos povos civilizados. Os allemães ultimamente porém declararam que isso tudo era invenção dos povos fracos, e que o Direito Internacional precisava ser modificado no sentido de permittir aos fortes usar de sua força, tão trabalhosamente adquirida, e mantida com tanto sacrificio, na paz armada. E' o mesmo que, amanhan, uma parte de membros mais fortes em uma sociedade culta, declarar que se constitue em classe para opprimir os fracos, seus irmãos na communhão social.

Amanhan, os militares allemães pódem declarar fóra da protecção legal as mulheres e crianças allemans, para serem coherentes com o que hoje sustentam relativamente á humanidade culta. Foi entretanto Ihering, jurista allemão, que doutrinou não haver, em uma sociedade, um unico membro inutil, lembrando que, num estabulo, entre os humildes, ameaçado de morte pelos poderosos da terra, nasceu Aquelle que transformaria a face do universo, que quebraria as cadeas dos escravos, proclamaria a egualdade do genero humano, cuja redempção vinha fazer... E Ruy Barbosa recordava á orgulhosa patria de Goethe que ella era uma nação insignificante, quando seus filhos derramavam luz sobre o mundo, que o Antigo Testamento, os poemas homericos, a Divina Comedia, e o renascimento italiano tinham apparecido em pequenos Estados. Comparemos o que fizeram Portugal e a Hollanda 
pela humanidade com o que faz hoje a Allemanha, e... passemos a narrar os crimes dos subditos do Kaiser aparceirados com elle. $010^{\circ}$ crime celebre, espantoso, praticado pela Allemanha foi o torpedeamento do Lusitania. O mundo inteiro tremeu de horror, ao ouvir a narrativa dessa hecatombe, e o Kaiser proseguiu na senda do delicto. Reconstruamos por um momento, e só de imaginar sentimos arrepiarem-se-nos os cabellos, reconstruamos ésta scena indescriptivel. Navega o transatlantico socegadamente, certos os passageliros de que, sob a segurança que lhes era dada pela civilização, podiam dormir tranquillos. Da-se o ataque. E' a morte que os surprehende. E' a morte inesperada. Surge a confusão a bordo. Ninguem se entende. $O$ instincto de conservação leva aos mais crueis actos. $O$ capitão tenta manter a ordem: não é obedecido. As mulheres choram em soluçoso pranto, as creanças são abraçadas pelas mães extremosas, que imaginam que esses pequenos seres, "em tanto amor gerados e nascidos", vão servir de pasto aos monstros marinhos, infelizes mães que vêem as tenras carnes de seus filhinhos despedaçadas, ainda palpitantes, pelos vorazes animaes que se occultam nas profundezas do oceano. E' lá que as miseras creaturas vão ter seus corpos dilacerados, perdendo a vida entre soffrimentos cruciantes, indiziveis.

E o mar furioso continua a rugir avido da preza que a Allemanha lhe fornece, esporeando, com suas ondas espumantes, o costado do navio que vae submergir-se. E o navio aderna de popa, levantando a prôa, como si tentasse fazer uma queixa aos ceus; como si pedisse ao Todo Poderoso um raio que fulminasse os maldictos corsarios, os piratas assassinos que lançavam aos abysmos insondaveis do oceano tantas victimas. Faz lembrar a tragica descripção do naufragio de Ulysses, sonhado pela imaginação do genio florentino, nesses terriveis e ao mesmo tempo delicados versos, que, em um terceto, en- 
cerram toda a imagem da lugubre scena, fechando-se a narrativa por um hendecasyllabo sublime, onde se contem todo o horror de uma tragica morte, hendecasyllabo só comparavel ao ultimo hexametro da Eneida:

"Tre volte il fé girar con tutte l'acque

"Alla quarta levar la poppa in suso

“E la prora ire in giú, com'altrui piacque

"Infin ch'il mar fu sopra noi rinchiuso.

$$
* * *
$$

Por uma bella manhã de Maio, nestas doces alvoradas tropicaes, ao rosicler da aurora, recebeu a capital do nosso Estado, no frio laconismo da linguagem telegraphica, a tremenda noticia do naufragio do Lusitania. Serena era a atmosphera, os operarios alegres passavam cantando, o Sol começava a atirar seus raios ainda frios sobre a cidade mal desperta, a vida intensa das manhans nevirosadas de Mai mostrava-se por toda a parte. Não podiamos nós brasileiros, homens de coração, crer em tal atrocidade, e a esta antithese entre a vida alegre da cidade laboriosa e a idéa da morte de centenas de mulheres e de creanças louras e innocentes apparecia a todos como sendo um sonho, uma coisa incrivel, um pesadelo: seria possivel neste seculo, de paz e de trabalho, tanta barbaridade? E a muitos lembrava o sonoro, mavioso e sublime verso da musa melancolica do poeta que annunciou a vinda de Jesus:

"At sperate deos memores fandi atque nefandi"

Tremei, ha, no Ceu, um Deus que vinga os opprimidos pelos poderosos da Terra! 
O outro crime celebre é o assassinato dé Miss Cavell. Sabem todos que ella era accusada de se ter negado a entregar ás autoridades allemans os ingleses que se haviam refugiado sob seu tecto. A's duas horas da madrugada, no pateo da prisão de Bruxellas, deveria ella ser arcabusada. No momento porém de se collocar no posto fatal onde havia de receber as balas dos bravos soldados do Kaiser

(Contra uma dama, ó peitos carniceiros,

Feros vos amostraes e cavalleiros!)

cahiu em desmaio. A vèrsão geralmente acceita é a de que os proprios algozes, sentindo o despertar dos brios militares dentro do peito, recusaram-se a fazer fogo sobre a infeliz inglesa. $\mathrm{O}$ official que commandava a execução approximou-se então de Miss Cavell, e desfechou sobre ella um tiro que lhe despedaçou a cabeça... Que differença entre este official, e o que no Mexico foi incumbido da execução do principe Maximiliano! $\mathrm{O}$ americano procurou o condemnado, na vespera da execução, e fez-lhe sentir que cumpria o dever de soldado, que obedecia a uma ordem legal que the fôra dada pelos seus superiores. $\mathrm{O}$ principe respondeu que não lhe queria mal por isto. Eis ahi o cavalheirismo do soldado da peninsula iberica. Eis ahi a brutalidade, a crueldade, a ferocidade do povo que se diz, ou se julga predestinado. Comparemos o brio do nosso irmão, descendente dos cavalheiros hespanhoes, com a baixeza de sentimentos do monstro que assassinou friamente uma innocente, individuo que, num baraço, deveria pagar seu crime nefando. Mas, fóra esse homicidio celebre, a Allemanha continuou na mesma senda de crimes e de violações de todas as leis acceitas pelos povos civilizados. Não trepidou em torpedear todos os navios que, de qualquer modo, the eram suspeitos de auxiliar, exercendo um commercio licito, os alliados. 
Conscia de seu crime, da monstruosidade de seus actos, do mesmo modo que os delinquentes vulgares, procurou apagar o rasto deixado na pratica do crime, e ordenou que os torpedeamentos fossem feitos sem que deixassem. vestigios.

Assim procedem os salteadores, quando assassinam os viajantes, dizendo que os mortos não podem denunciar. A hypocrisia é, ninguem o contestará, um preito á virtude. E' a consciencia do delicto que leva a Allemanha a buscar apagar seus traços. Nas paredes da cathedral de Reims, Leon Bourgeois encontrou um cartaz, feito por ordem das autoridades allemans, e concebido nos seguintes termos: "Afim de garantir a segurança de nossas forças e a calma da população de Reims, as pessoas abaixo arroladas foram tomadas como refens pelo general commandante do exercito allemão, e serão arcabusadas á primeira tentativa de motim. Além disso a cidade será inteiramente queimada e os habitantes enforcados." Segue-se a lista dos homens de importancia encarcerados como sendo refens. E ha, no Brasil, em nossa amada patria homens que se dizem germanophilos!

Passaremos sem menção o incendio da bibliotheca de Louvain, o já tão conhecido canhoneio da cathedral de Reims, e só nos cumpre lembrar que, após a declaração de guerra, a Allemanha tractou com a maior brutalidade os estrangeiros que se achavam dentro de seu territorio. Damas americanas foram esbofeteadas, unicamente por haverem protestado contra a grosseria germanica, os embaixadores da Russia e da França foram injuriados, e até a pobre imperatriz da Russia, viuva octogenaria, foi maltractada... Nunca soube ao certo, o povo brasileiro, e foi o discreto silencio uma medida de prudencia, o que soffreu nosso diplomata Amaral Gurgel, ao tempo da ruptura de nossas relaçóes com a Allemanhia. O catalogo de crimes é interminavel. O incendio é systematicamente 
usado. Em Termonda, na Belgica, houve corpos do exercito allemão incumbidos exclusivamente de saquear, e, em seguida, queimar tudo, até mesmo os hospitaes, onde se achavam doentes em estado grave. Parecia que reproduziam os soldados allemães actos dos salteadores da Franconia, com tanta vida descriptos por seu compatriota Schiller. Em Haut de Vermont, fizeram um morticinio de cidadãos inermes, entre os quaes velhos de 60 annos e crianças. Como um desses infelizes arcabusados ainda désse signaes de vida, regaram-no de kerozene, e lançaram fogo sobre as roupas do moribundo. Em uma aldeia belga, fizeram o que nunca foi mencionado nos annaes das crueldades humanas, salvo nos antigos tempos: mataram todos os habitantes da localidade. Em Nancy, arcabusaram, entre outras pessôas, uma mulher gravida. Por terem encontrado um papel pregado á parede da casa de um sacerdote, e suspeitando, ou fingindo suspeitar, que era alguma planta relativa ao theatro da guerra, arcabusaram. tres sacerdotes.

Na Belgica, em diversas localidades do Hainaut, collocaram crianças e mulheres belgas que haviam aprisionado, diante de seus batalhões, e por traz desses infelizes faziam fogo sobre os belgas! $O^{\prime}$ bravos cavalheiros, isto é que é valor! Vossos nomes hão de passar á posteridade, ao lado dos daquelles soldados que foram dispensados do serviço militar por... excessivamente corajosos. $O$ official allemão A. Eberlein referiu, em um jornal allemão de nome arrevezado, o que elle fizera á tomada de Saint Dié. Disse que teve a bôa idéa (poderia ter dicto excellente) de se apoderar de alguns paisanos, e de os collocar nos pontos para onde convergia o fogo dos belgas. A medida deu optimo resultado, mas os innocentes foram sacrificados (não obstante o cuidado dos belgas) pelas balas de seus irmãos. Isto não nos causa só indignação, mas tambem nojo. E é gente do caracter de Eberlein que 
diz que vae reformar a moral do mundo hodierno. Basta! Vós deveis ter agora a sensação dos que revolvem podridóes, dos que procedem a exhumaçóes, dos que passam junto de um corpo em putrefacção, e esse corpo que se decompõe, á face do universo, é o do povo allemão. Não precisa o allemão só de que lhe atiremos balas, mas tambem de que lhe lancemos sobre o cadaver putrefacto, uma pá de cal. Mas, como explicar essa decomposição de um organismo que nenhum symptoma mostrou, sinão ultimamente, de seu estado de corrupção? Diz-se que a Allemanha enlouqueceu. Não é novo o caso. Uma das mais bellas paginas do poema immortal de Virgilio é a do comeco do canto $6 .^{\circ}$, quando a furia Alecto enche de ardor bellicoso os Rutulos. Penetra nos palacios. Infiltra nas veias dos principes e das princesas o veneno de uma das serpentes que traz sobre a cabeça. Atira aos peitos de Turno uma tocha ardente. Faz a rainha Amata embrenhar-se nos densos bosques, para offerecer a Baccho sua filha Lavinia, e depois se lança entre as mulheres latinas, convidando-as a soltar os cabellos, arrojar de si as fitas que os prendem, e começar com ella a orgia sagrada. Torna louca uma matilha de cães dos troyanos. A musa do poeta dá-nos perfeita idéa do sopro de loucura que passava pelos habitantes da região, dominados pelo espirito maligno de Alecto. Hoje a sciencia explica o phenomeno com vasta copia de conhecimentos, e muito menos de poesia, embora com extraordinaria prodigalidade de citações, que tanto nos esclareceram, quanto as razões dadas pelo poeta latino em seus bellissimos hexametros. Acabo de ler um eruditissimo artigo do Professor Dumas, estudando o contagio da loucura. O professor, cujas bellas conferencias têm deliciado os brasileiros, cita umas dezenas de mestres de Psychiatría partidarios da doutrina do contagio, enumerando os trabalhos de Marandon de Montyel, Arnaud, Verga, Knittel, Guiard, Clerambault, 
Calmus, Witte, Benon e Wilcox. Muitas dessas obras são escriptas na lingua que nós, homens delicados da raça latina, com difficuldade pronunciamos, na lingua do Kaiser.

O que nos interessa porém é que certamente o professor Dumas não discutiria a these do contagio em uma de suas bellas conferencias, mas só a estudou nas paginas de uma revista philosophica. 0 phenomeno notavel porém de ficar subitamente um povo louco ahi está, sem apparecer quem conteste tão extranho facto. Os crentes, com Virgilio, deram sempre ao lastimavel successo a explicação do poeta romano. "Quos vult Jupiter perdere dementat prius", disse um. Racine, o suave, o doce, mavioso e sublime Racine, tambem cantou:

\footnotetext{
"Daigne, daigne, mon Dieu, sur Mathan et sur elle

"Répandre cet esprit d'imprudence et d'erreur,

"De la chute des rois funeste avant coureur...
}

Que nos importa, de facto, a ethiologia da loucura de nossos aggressores? Que nos adianta que tenham elles sido feridos por um castigo celeste, ou que tenha sido seu mal consequencia de uma fatalidade, ou combinação de circumstancias, ou mesmo de seu modo condemnavel de vida? Que nos importa indagar si, até certo ponto, são os loucos responsaveis por seus crimes, ou si sua irresponsabilidade é, como sustenta a maioria dos criminalistas, absoluta, e dá-se em qualquer grau da loucura? Nada disto nos interessa. O que nos resta saber é si os allemães estão loucos, e então teremos o direito de tomar contra elles as medidas de defesa que tomamos contra os alienados, quando estes póem em perigo nossa vida e nossos bens. A humanidade deverá, acudindo ao appello de Hervé, atirar, sem piedade sobre essas hordas de loucos sanguinarios. Convém comtudo lembrar uma 
particularidade que Bagehot observou, e que, tantas vezes, tem sido confirmada pelos sociologos. E' ella a tendencia de imitarem os homens aos seus superiores. Num jornal, tomam todos os collaboradores o tom do redactor chefe. Numa sociedade, os empregados seguem os habitos, o modo de viver, de falar, de andar do socio, ou dos socios que a dirigem. Nos Estados, ha a tendencia para imitar o chefe, e, até em seus defeitos, é elle copiado. Ora, sabido é que o Kaiser é um epileptico, e a tára do sangue real antigo foi em versos peregrinos cantada e eternizada no Aiglon, pelo genio de Rostanḍ. Em plena rua, na Hollanda, teve o Kaiser, ha alguns annos, um desses ataques classicos, que não podem illudir ainda o menos observador, e inutil é referir-vos a fatalidade que pesa sobre os que têm o grande mal. Explodindo no Kaiser a loucura, certamente nada tem de admiravel que lhe imitasse a loucura o povo. Mas deixemos considerações medico-sociologicas, e vejamos os factos. O pangermanismo foi, é certo, pregado por Hegel, o pantheista tão conhecido, que, no principio do seculo XIX, sustentava que o mundo pertencêra a tres grandes imperios, o oriental, o grego e o romano, e que deveria agora tocar á Allemanha, ou ao imperio germanico. Ora, depois disso, sempre houve allemães que têm tomado a sério ésta idéa delirante do maluco de Heidelberg, mas quem mais importancia lhe ligou foi Guilherme $2 .^{\circ}$, imitado por grande numero de seus subditos. Como ainda não conseguiram, nem certamente conseguirão submetter, pelas armas, a humanidade ao seu imperio providencial, adoptaram os pangermanistas o commodo systema de reconhecer que ha uma Allemanha no sentido restricto, que é formada pelas terras ora occupadas pelos individuos que prestam de facto obediencia ás suas leis e ás suas autoridades, e uma Allemanha no sentido lato, comprehendendo terras que elles deverão conquistar ou submetter, entre as quaes 
se acha o sul de nossa patria, já considerado rebelde por se reger pelas leis de nossos avós, e prestar obediencia ás autoridades que constituimos. Não é só. Ha, na Allemanha, um jornal intitulado Heimdall, do nome de um deus germanico. Este jornal é protegido e auxiliado por professores, funccionarios publicos, homens celebres no magisterio, e, entre elles, achou-se o proprio Felix Dahn ha pouco fallecido, e que nenhum jurisconsulto brasileiro póde deixar de conhecer. Por vinheta, tem esse periodico uma gravura que representa o Olympo dos deuses escandinavos. A' esquerda, Heimdall, deus da aurora e sentinella dos deuses, toca uma trombeta para chamar todos ao combate, á conquista dos territorios que devem completar a Allemanha. A divisa escripta em caracteres runicos debaixo da gravura, explica o que comprehende ésta Allemanha na Europa. Diz assim: "Do Skagen ao Adriatico; de Bolonha ao Narva, de Besançon ao Mar Negro". Lembra-nos Paulo Verrier, de quem tiramos ésta noticia, que, na mythologia dos escandinavos, Heimdall chama por uma tuba canora, os deuses e os guerreiros eleitos á defesa do Valhall (Olympo dos deuses scandinavos) e do mundo dos homens contra o ataque de seres inferiores e damninhos, gigantes das nevoas e do fogo, lobos e serpentes monstruosas, e é claro que, na allegoria da gravura, os homens são os allemães, e os animaes repugnantes, os anglosaxonios, os latinos e os slavos. Não é só isto o que quer o jornal. Elle tem um programma, e idéas que vulgariza. Entre outros planos, ha o da formação da pequena, e da grande Allemanha. A pequena comprehenderá os povos propinquos dos allemães, como são os scandinavos de raça mixta germanizados.

Da França, por exemplo, serão conservados 10 milhões de habitantes germanizaveis, adaptaveis á cultura alleman, e os demais serão exterminados!... Em 
certas regiões, os allemães deverão ser os unicos a ter direitos civis e politicos, ficando os individuos de outras raças reduzidos á condição de servos. Isto porém não é, como á primeira vista parece, simples crueldade, mas rematada loucura. Pois será crivel que não veja a Allemanha a impossibilidade de se manter, em pleno seculo $\mathrm{XX}$, em um tal regimen? Não vê que o regimen colonial está definitivamente reconhecido de impossivel manutenção pela força, salvo em relação a povos atrazadissimos? Ignoram os professores que redigem o Heimdall, o que foram as luctas das colonias contra as metropoles durante o seculo XIX? Será crivel que a allucinação vá ao ponto de obcecar a Allemanha de modo a tornar-lhe impossivel ver que, si ousasse, em nossa cara patria, impor a servidão ao altivo sertanejo, ao audaz cavalleiro do Rio Grande do Sul, teria a sorte que teve a França quando Juarez venceu a Maximiliano? Gonçalves Dias,' ao cantar a grandeza do gigante de pedra, que, sentinella vigilante, guarda a bahia Guanabara, apostrophou-o, em uma bella ode, para que se precipitasse sobre o mar, no dia em que o estrangeiro dominasse em nossa patria. Póde o gigante de pedra dormir socegado, tranquillo o seu somno secular, deitado sobre a mais bella região do universo, que, emquanto houver brasileiro digno desse nome, emquanto viver a geração actual, não terá elle necessidade de se lançar ás ondas indomitas dos bravios mares da terra onde canta a jandaia nas frondes da carnauba.

Deixem-se os allemães ficar ás margens do Rheno, que aqui ha ainda os descendentes dos bravos que, em 1822, sacudiram o jugo do mais heroico povo do universo, que foi o portugues. Vejamos ainda outros factos reveladores da loucura germanica, e particularmente de seus chefes. Muito tardiamente contestou-se ésta phrase do Imperador da Allemanha: "E' de minha real e imperial vontade que, antes de tudo, seja esmagado o ridiculo e 
desprezivel exercito ingles do general French". E quando foi feita a contestação? Quando, depois de se ver a impossibilidade de ser realizada essa ameaça, filha da mania da grandeza, se mostrou quão ridicula era ella. Além disso, o jornal "Noticia de Hamburgo", a 28 de Agosto de 1914, deixou escripto, e portanto impossivel é a contestação, ou a denegação mentirosa da bravata reveladora da megalomania: "Nós devemos mostrar á Russia a superioridade de nossa cultura e de nosso poder militar. Devemos obrigar a França a curvar-se sobre os joelhos até ser suffocada". E, no Marne, em Verdun, viram os megalomaniacos quão enganados se achavam: a França subiu, si possivel era subir o glorioso paiz no conceito do mundo culto, na Historia dos povos generosos e bravos, de modo a dever ser considerada como verdadeiramente o typo de imitação de todos os Estados que se querem ver respeitados, e occupar um posto elevado na humanidade. Com razão pois disse o norte americano Whitridge: "Os allemães enlouqueceram sob a dupla influencia do militarismo e da contemplação exclusiva de sua grandeza, de seu poder, de sua força". E como não haviam de chegar os allemães a essa megalomania, si cultivavam as doutrinas de Nietzsche, com maior carinho que as do proprio Hegel. Ouçamos Nietzsche: "Fazei, obtende, sêde tudo quanto vos permittir vossa força.

A piedade é um vicio. A evolução é a supervivencia do mais apto, e a destruição do menos apto. $\mathrm{O}$ christianismo, com sua moral de sympathia para com os pobres de espirito, foi uma molestia da decadencia. 0 mundo pertence aos que têm poder para o dominar; tractados, convenções pacificas, juizos arbitraes, não passam de actos de astucia estrategica para illudir as nações; venha a guerra com a sua realidade terrivel, e tudo isto desapparece, e é esquecido. A sympathia para com a fraqueza e o soffrimento é tambem uma fraqueza; a força é a prova 
suprema do Direito. Quẹ crê nesta moralidade superior tem a seu dispor o mundo que acredita nas antigas virtudes hoje fóra da moda". A' vista desta moral, não é de admirar que o Kaiser, devoto de Heimdall, houvesse declarado que os tractados são trapos, retalhos de papel sem nenhum valor. Em uma de suas elegantes e chistosas chronicas, o satyrico, o mordacissimo escriptor português, Eça de Queiroz fez a observação de que o Kaiser se exprimia sempre no presupposto de que era socio e alliado de Deus. Chronologicamente examinando o modo de proceder do Kaiser a ésta luz, emittiu o conceito de estar o Kaiser, aos poucos, deixando Deus em um segundo plano, e gradativamente tomando, de modo nefando, o logar da Providencia. Este acto de irreverencia, impiedade, profanação do nome de Deus, este modo blasphemo de se exprimir, era, observava o conceituoso chronista, prova de um desiquilibrio mental, uma fórma de mania religiosa. Mas, si a psychose do chefe chamou a attenção do grande literato português, não é menos verdade que os pequenos, os allemães do povo tambem estão affectados do mesmo desarranjo mental. Têm-se todos por empregados do Todo Poderoso, seus prepostos de confiança; e, infelizmente, em seu espirito toldado, entenebrecido pela molestia, confundem o verdadeiro Deus com Heimdall, a bellicosa divindade da mythologia dos scandinavos. Ahi temos a mania das grandezas unida á religiosa, um orgulho sem limites ligado a um fanatismo estolido. Apreciemos um outro facto comprobatorio da perturbação mental da gente d'Além Rheno. Já vimos que se enganaram os allemães, em suas previsões, no começo da guerra, suppondo que a Inglaterra não tomaria parte na lucta contra elles, que a Italia marcharia ao lado delles, que a Belgica lhes daria passagem, e que o Japão, em consequencia de uma carta amavel do Kaiser, viria prestar apoio ás armas germanicas. A desillusão 
foi grande. Tudo falhára. Ficaram logo detidos em sua marcha sobre Paris, e não puderam vir fazer a orgia impia, abominavel, que contavam realizar na cidade que é o orgulho da civilização moderna, na bella e culta Paris. Depois... continuam a depredar em terra, e a piratear no oceano. Collocam-se nas fronteiras da França, e ahi permanecem damnificando. Mantêm-se occultos em submarinos no mar, atacando os viajantes pacificos. Durante mais de tres annos estão a fazer investidas inuteis para elles, e mortiferas para os exercitos do Kaiser e dos povos civilizados. Não se fatigam de guerra. Sabem que não vencerão, que não poderão vencer, e continuam na guerra, sem um fim, sem um intento, sem um escopo nobre, alevantado, fazendo em summa a guerra pela guerra, semelhante ao louco que, no hospital, executa sempre o mesmo movimento, sem um fim apreciavel, ou ao menos, que se justifique aos olhos das pessôas sensatas. A Allemanha conserva o povo em armas, nos campos sangrentos da lucta, sem que seja possivel se dizer para que fim. Contida na Belgica, batida no Marne, desmoralizada em Verdun, onde fizeram os francêses a mais epica resistencia de que dá noticia a Historia, detida no Oriente, repellida na Italia, vae agora provavelmente tentar passar pelos invios montes da Suissa. Quem sabe si, practicada mais ésta loucura, terá um momento lucido, e reconhecerá seus crimes, sua loucura, pedindo de joelhos á humanidade perdão do crime mais atroz que tem commettido um povo. Por emquanto a lucta está travada na região que recorda as glorias do povo romano. Foi no logar em que hoje se batem heroicamente os filhos da bella Italia, que seus antepassados colheram louros immarcesciveis, e é lá que serão vencidos os audazes invasores. Ao contemplar as aguas sempre agitadas do ardego mar Adriatico, os cimos nevados dos Alpes, o cursc magestoso do Pó, aquelle que era considerado por Virgilio 
como sendo o rei dos rios, e que, quando Cesar cahiu ferido pelo punhal homicida, tomando parte na colera dos bons cidadãos, deixou indignado seu leito, inundou as selvas, arrasou rebanhos, e, com suas aguas vorticosas, destruiu quanto achou ás suas margens, ao admirar essa natureza bellissima da mais accidentada região do mundo, onde as campinas sem fim alternam com as asperas montanhas, relembrarão os gloriosos filhos da Italia que. houve, na antiguidade, Roma, cuja grandeza procura a Allemanha usurpar, nada mais sendo entretanto que um arremedilho daquelle colosso que assombrou, e assombra ainda a humanidade culta, pela sua grandeza em tudo quanto póde ambicionar o espirito humano. Inspirados nos mais elevados ideaes, ambicionando manter a gloria passada, seguros de seus direitos, os bravos que hoje se batem na região invadida pelos allemães, ao norte da Italia, saberão repellir o audaz inimigo, e legarão aos posteros um nome que poderá figurar ao lado do deixado pelos soldados de Cesar e dos outros heroes antigos. Que pretendem pois os subditos do Kaiser naquella região onde a soberba Veneza se banha nas aguas do Adriatico? Oh, rada mais que o que fazem certos dementes, a saber assassinar, destruir, sem um fim razoavel. E é a vós, filhos da Italia a quem ésta terra hospitaleira abriu os braços, a vós que nesta região encontrastes uma segunda patria, que cumpre, unidos aos brasileiros, sempre vossos irmãos, na paz, do mesmo modo que na lucta contra o invasor, é a vós que cumpre partir em auxilio dos vossos irmãos que, nas margens do Tagliamento, defendem os patrios lares. Não ha muito, nesta mesma terra em que vos falo, habitavam os primeiros posseiros attrahidos pela uberdade -do solo. A região era inculta, e, na floresta secular, quebravam-se os écos do trabalho afanoso dos primeiros entrados nesta terra abençoada. Ao longe, os campos louros do Mogy faziam contraste com a vegetação 
negra da matta, que era derribada para a plantação dos primeiros cafezaes. Rudes braços e muita coragem possuiam os pioneiros e fortes immigrantes europeus, quasi todos italianos. Agro sertão, não os atemorizava pela difficuldade de sua cultura essa bella terra, verdadeira Terra da Promissão. Rasgavam o solo uberrimo, cortavam as arvores gigantescas, drenavam as terras pantanosas, plantavam, e sentiam essa alegria que dá a esperança fundada da abundante colheita. Eram fortes e corajosos. Não trepidavam na lucta com a natureza sertaneja. Pois bem! Vós sois os descendentes desses fortes. Sabeis que a Italia vae conceder amnistia aos que não accudiram ao $10^{\circ}$ chamado, por não conhecerem o perigo que corria a mãe patria. E' a vós que cabe, deixando a lucta com a terra, iniciar a lucta com os barbaros, em defesa da civilização que hoje periclita, ameaçada pelas hordas de allemães que reproduzem as scenas de vandalismo de que foi victima a Europa culta, e particularmente o imperio de Roma, quando Alarico, Radagasio, e Attila derramaram sobre a peninsula suas hostes aguerridas e devastadoras. Não fôra a bravura de vossos avós, e teriam os barbaros ido profanar a cidade eterna, a cidade santa. Deveis este serviço á patria e á humanidade, vós, a quem o Novo Mundo abriu os braços, que achastes a fartura, a riqueza neste solo abençoado, porque tendes deveres para com a humanidade, e, quando, o que não posso figurar sinão com horror, fosse possivel apagar-se em vosso peito todo sentimento nobre, cumpria a vós considerar que, aqui mesmo, não estaremos seguros no dia em que as armas victoriosas do Kaiser puzerem em perigo. a independencia da Italia, e houverem conseguido a realização desse terrivel sonho de dominio universal, ficando o mundo entregue a uma nação de loucos, que não tem a mais leve noção de moral, homens cujo espirito entenebrecido só deseja morticinio, carnificina, saque, incen- 
dio... Corre a todos o dever de luctar contra essa onda que ameaça a civilização occidental, e que, quando pudesse vencer, não deixaria em paz a joven America, cujo solo ubertoso tanto ambiciona. E' tempo de despertar, é tempo de reconhecer o perigo que nos ameaça. Faço votos para que minha voz tenha sido ouvida como si fosse a de um propheta exercendo o duro ministerio de dizer, com crueza e sem ambages, a difficil e dolorosa situação em que se acha o povo brasileiro, em que se acha a America, em que se acha toda a humanidade culta.

Braz de Sousa Arruda,

Docente da Faculdade. 